\title{
Increased Incidence of Stress-related Tic Habit Cough in Children During the Recent Greek Financial Crisis
}

\author{
ATHINA PAPADOPOULOU ${ }^{1}$, DESPOINA-ZOE T. MERMIRI ${ }^{1}$, GEORGIOS GRITZELAS ${ }^{2}$, \\ OURANIA TSOURIDI ${ }^{3}$, ELENI DIMARA ${ }^{1}$, CHRISTOS YAPIJAKIS ${ }^{4}$ and GEORGE P. CHROUSOS ${ }^{5}$ \\ ${ }^{1}$ Allergology and Pulmunology Unit, Penteli's Children Hospital, Athens, Greece; \\ ${ }^{2}$ Child Psychiatry Section, Penteli's Children Hospital, Athens, Greece; \\ ${ }^{3}$ Psychology Section, KAT General Hospital, Athens, Greece; \\ ${ }^{4}$ Unit of Orofacial Genetics, $1^{\text {st }}$ Department of Pediatrics, School of Medicine, \\ National and Kapodistrian University of Athens, "Aghia Sophia" Children's Hospital, Athens, Greece; \\ ${ }^{5}$ University Research Institute of Maternal and Child Health \& Precision Medicine, \\ and UNESCO Chair on Adolescent Health Care, National and Kapodistrian University of Athens, Athens, Greece
}

\begin{abstract}
Background/Aim: Tic habit cough (THC) is not easily recognized and requires a high index of suspicion. Since there is evidence for stress-related etiology, the study presents our experience during the eight-year period of the recent Greek financial crisis. Patients and Methods: This is a descriptive prospective cross-sectional clinical study using a consistent approach to diagnosis, possible triggers and treatment options. Results: Fifty-one children (26 girls, age 9.5 $\pm 3.1 y$ ) from a total of 3,793 new referrals for chronic cough fulfilled the criteria of THC (1.34\%). Incidence rates per 1,000 person-years were $1.34(95 \% C I=0.34-5.40), 3.91$ (95\%CI=1.86-8.19), $4.03(95 \% C I=2.01-8.06)$ and 14.60 (95\% CI $=10.43-20.44)$ for every two years. Poisson analysis showed an increased trend during the four time periods with an incidence rate ratio equal to 2.21 (95\%CI=1.58-3.09, $p<0.001)$. THC was mainly attributed to learning difficulties, as well as stress-related impact of peer or family bullying, family financial problems and child anxiety disorders. Conclusion: The incidence of THC is associated with the negative aspects of stressors during a period of financial crisis. The potential underlining psycho-physiological mechanisms are discussed as well as the fact that prompt diagnosis may result in successful interventions.
\end{abstract}

This article is freely accessible online.

Correspondence to: Dr. Athina Papadopoulou, MD, Allergology and Pulmunology Unit, Penteli's Children Hospital, 8 Ippokratous str, Penteli, GR15236, Athens, Greece. E-mail: athinapap@yahoo.com

Key Words: Tic habit cough, cough reflex, lifestyle, stress, cognitive behavioural therapy.
Persistent involuntary cough without an identifiable organic cause has been labelled with various descriptive terms, such as "functional", "psychogenic", "operant", "honking" or 'habit' (1-7). However, the term tic habit cough (THC), suggested by the Chest expert panel report on Somatic and Tic cough in 2016, best describes this entity (8). Cough occasionally starts after a mild upper airway infection but persists as a dry, repetitive, loud and involuntary cough. It is usually observed during daytime and never disrupts sleep or worsens during exercise. Children look 'happy' in contrast to their parents who look worried, while everyday life and social activities remain undisturbed. THC is initially misdiagnosed as asthma, however, clinical and laboratory evaluations are characteristically normal, while therapeutic interventions including bronchodilators, corticosteroids and antibiotics are ineffective (9). Moreover, stressors originated from modern lifestyle such as learning difficulties, divorce, death and bullying have been reported as potential triggers, although there has been no clear etiologic correlation. A positive response to behavioral modification therapy or psychiatric support constitutes one of the clinical diagnostic criteria and enhances the correlation of stressful events to THC $(10,11)$.

THC is a diagnosis of exclusion and should always be included in the differential diagnosis of chronic cough (10). However, its prevalence is hard to establish and the reported rates represent underestimates, probably due to low awareness in the medical community on the one hand, and the lack of validated diagnostic criteria on the other $(5,6$, 12-16). Alternatively, an increase in awareness of the medical personnel leads to the increase in recognition of THC cases as this was depicted by Weinberg $\mathrm{M}$ et al. (17).

Bearing that in mind, THC was highly ranked in the differential diagnosis of all newly referred cases with chronic 
cough in our department. This study presents our experience during an 8-year-period of major financial crisis in Greece (2009-2016), using a consistent approach to diagnosis, possible triggers and treatment options. Additionally, every effort was made to unravel any mental or emotional strains or tensions that were possibly considered responsible for the children's symptoms. Even though the pathways that link stress and cough are largely obscured, possible underlining pathophysiological mechanisms are discussed linking children's psychology to cough reflex physiology.

\section{Patients and Methods}

A descriptive, prospective cross-sectional study was conducted during an 8-year-period of major financial crisis in Greece (20092016). New cases with chronic or recurrent cough visiting the Unit of Allergology and Pulmunology at Penteli's Children Hospital were referred and extensively evaluated.

Diagnostic criteria. THC was suggested if the patients manifested the core clinical features of tics, namely, suppressibility, distractibility, suggestibility, variability and the presence of premonitory sensations (8). The differential from somatic (psychogenic) cough followed the published criteria (18). Cases fulfilling all major and at least two minor characteristics were considered to have THC (Table I). The diagnosis was established only if two independent physicians agreed on the same diagnosis, extensive workup for organic causes of cough was negative and any therapeutic attempt was unsuccessful. Psychiatric evaluation was done using DSM-5 criteria for psychiatric/ anxiety disorders (18). The Hamilton Anxiety Rating Scale (HAM-A) was used to measure anxiety $(10,19,20)$.

Data assessment. Detailed data for presenting symptoms and personal past medical as well as family histories were recorded. Demographic characteristics and social background were also examined and registered. Highly educated parents were defined if they possessed a Ph.D. degree. FBC, immunoglobulins, skin prick tests to common aeroallergens, pulmonary function tests, and chest$\mathrm{X}$ ray were performed in all children whereas ear nose and throat (ENT) evaluation, mannitol provocation test, flexible bronchoscopy and sinus computer tomography were done in inconclusive cases. In detail, ENT evaluation was done in cases with either atopic history or high levels of $\mathrm{IgE}$ and/or serum eosinophils, and a mannitol provocation test was done in three cases reporting non-evidenced asthmatic symptoms. Flexible bronchoscopy was performed in one boy with high serum eosinophilia to exclude eosinophilic bronchitis and sinus computed tomography (CT) was performed in one girl reporting severe, chronic nasal congestion. Any use of inhaled bronchodilators and steroids in the past were highlighted.

Stress evaluation. Psycho-social evaluation including detailed history for stressful events and family background were recorded in a personal interview by a psychologist and a social worker. The Coddington's Life Events Scale for children and Adolescents (CLES) was chosen as a baseline questionnaire in order to identify adversities. It was considered the most suitable scale for this study as it has been well validated, can easily be answered by the child or by parents and includes questions concerning social environment
Table I. Clinical criteria for tic habit cough diagnosis.

Major

- Dry cough, individually stereotypic, never disrupts sleep

- Stops or starts when suggested

- Not disruptive to normal daily or pleasant social activities

- Pharmacological treatment is ineffective

Minor

- "Barking" or "honking" quality

- Decreasing in frequency or severity when performing pleasurable social activities or exercise

- Worsening in the presence of parents, teachers, or health care professionals

- Usually associated with secondary gain (i.e. parental attention, missing school)

- Often preceded by upper respiratory tract infection

- Habitually accompanied by a "tickle" in the throat, a "chin-on-chest" posture or a hand-to-mouth gesture

- Patients exhibiting "la belle indifference" to their symptoms

- Rarely other tics coexist (nail biting, trichotylomania)

Tic-habit cough diagnosis was considered if all major and at least two minor clinical characteristics were present, and extensive workup for organic causes of cough was negative.

(21). Each mentioned stressful event was further clarified to ensure its link to THC initiation. In detail, learning difficulties were evaluated by assessment of cognitive function (IQ test) and of academic achievement whereas bullying reports were evaluated by assessing the school and home environment using the form of bullying scale (22). Financial problems were considered worth further exploring if any of the parents had lost his/her job or if the financial income of the family was reduced to half.

Psychotherapy. Cognitive behavioural therapy (CBT) was used as therapeutic intervention $(23,24)$. It combines cognitive therapy by investigating a child's thoughts, with behavioural therapy by reviewing the child's actions and feelings. The theoretical background of CBT is based on the fact that there is a relationship among thoughts, emotions and behaviours. Thus, CBT focuses on challenging and changing unhelpful cognitive distortions and behaviours, improving emotional regulation and developing personal coping strategies to solve current problems. CBT is a psycho-social intervention that was designed to treat a number of mental health conditions focusing on the present events using evidence-based techniques. After the first CBT intervention, children were followed up monthly for 6 months to evaluate their outcome.

Statistical analysis. Continuous variables are presented with mean and standard deviation (SD). Quantitative variables are presented with absolute and relative frequencies. The 8-year period was divided into 4 bi-yearly periods ( $\left.1^{\text {st }} 4^{\text {th }}\right)$ based on the fact that THC is a rare entity. For the comparison of proportions, chi-square and Fisher's exact tests were used. Student's $t$-test or nonparametric Mann-Whitney test were used to compare means and median values among time periods. Based on registered incident cases, incidence rates and respective confidence intervals (95\%-CIs) were estimated using the person-time method (incident cases/person-time). Dual year incidence rates are presented per 1,000 person-years (py). A significant increase in cases was detected during the last period of the study. Thus, a comparison of stressors and incidence was done 


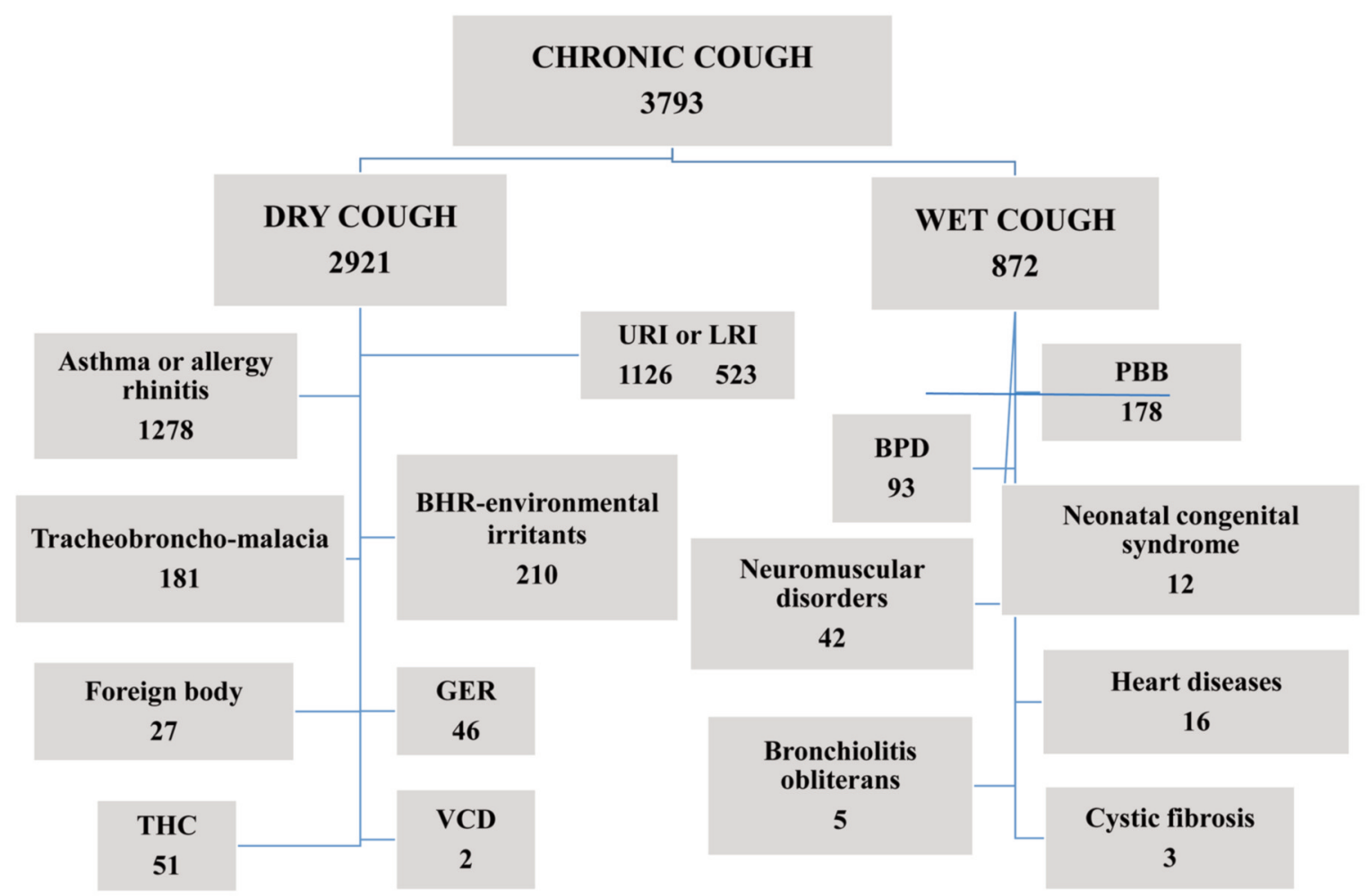

Figure 1. The main diagnostic entities related to the referred new cases with chronic cough. URTI: Upper respiratory tract infections, LRTI: lower respiratory tract infections, BHR: bronchial hyperresponsiveness, GER: gastroesophageal reflux, BPD: bronchopulmonary dysplasia, PBB: protracted bacterial bronchitis, VCD: vocal cord disease, THC: tic habit cough.

between the first three time period together $\left(1^{\text {st }}-3^{\text {rd }}\right)$ and the $4^{\text {th }}$ period of the study in an attempt to define possible related factors using the Poisson models. All $p$-values reported are two-tailed. Statistical significance was set at 0.05 and analyses were conducted using STATA statistical software (version 11.0).

\section{Results}

Incidences rates. Fifty-one children (26 girls, age 9.5 $3.1 \mathrm{y}$ ) from a total of 3,793 new referrals for chronic cough fulfilled the criteria of THC $(1.34 \%)$ in the eight-year period (Figure $1)$. Out of these, thirty-four $(66.6 \%)$ were diagnosed during the last two years $\left(4^{\text {th }}\right.$ period), representing a six-fold increase. Incidence rates per 1,000 py were equal to $1.34(95 \% \mathrm{CI}=0.34$ $5.40)$ for the $1^{\text {st }}$ period, $3.91(95 \% \mathrm{CI}=1.86-8.19)$ for the $2^{\text {nd }}$ period, $4.03(95 \% \mathrm{CI}=2.01-8.06)$ for the $3^{\text {rd }}$ period, and 14.60 $(95 \% \mathrm{CI}=10.43-20.44)$ for the $4^{\text {th }}$ period (Figure 2$)$. Poisson analysis showed an increased trend during the four time periods with an incidence rate ratio equal to 2.21 $(95 \% \mathrm{CI}=1.58-3.09, p<0.001)$. Also, the incidence rate ratio for the comparison of the last two periods $\left(3^{\text {rd }}\right.$ and $\left.4^{\text {th }}\right)$ to the first two periods $\left(1^{\text {st }}\right.$ and $\left.2^{\text {nd }}\right)$ was $3.54(95 \% \mathrm{CI}=1.72-7.28$, $p=0.001)$, while for the $4^{\text {th }}$ periods to all the others was 4.52 $(95 \% \mathrm{CI}=2.52-8.09, p<0.001)$.
Clinical outcome and laboratory values. The time spent from the onset of symptoms to diagnosis was $12.8 \pm 13.8$ months, ranging from 2-72 months (Table II). Eight cases $(15.6 \%)$ reported recent mild respiratory illness. Twelve cases $(23.5 \%)$ had asthmatic symptoms in the past and three $(5.9 \%)$ had allergic rhinitis with sensitization to house dust mites, grasses and olives. One patient reported an asthma attack during the last year. Routine laboratory workup, pulmonary function tests and chest X-rays were all normal. One patient had eosinophilia $\left(1,200 / \mathrm{mm}^{3}\right)$ and another $\operatorname{IgE} 379 \mathrm{U} / 1$, without sensitization or history of allergic disease. ENT evaluation and mannitol provocation test that were performed in the aforementioned cases were negative. Flexible bronchoscopy showed non-specific inflammation of the respiratory tract, excessive dynamic airway collapse (EDAC) of the posterior area and normal cytology. Sinus CT revealed moderate hyperplasia of inferior turbinate. Eleven cases (21.6\%) reported atopic family history. Half of the parents were smokers, of whom $57.7 \%$ smoked at home. The parents of 6 children $(11.7 \%$ ) experienced depressive or anxiety disorders.

Stressors. According to the psycho-social evaluation, THC was mainly related in 12 cases $(23.5 \%)$ to learning 


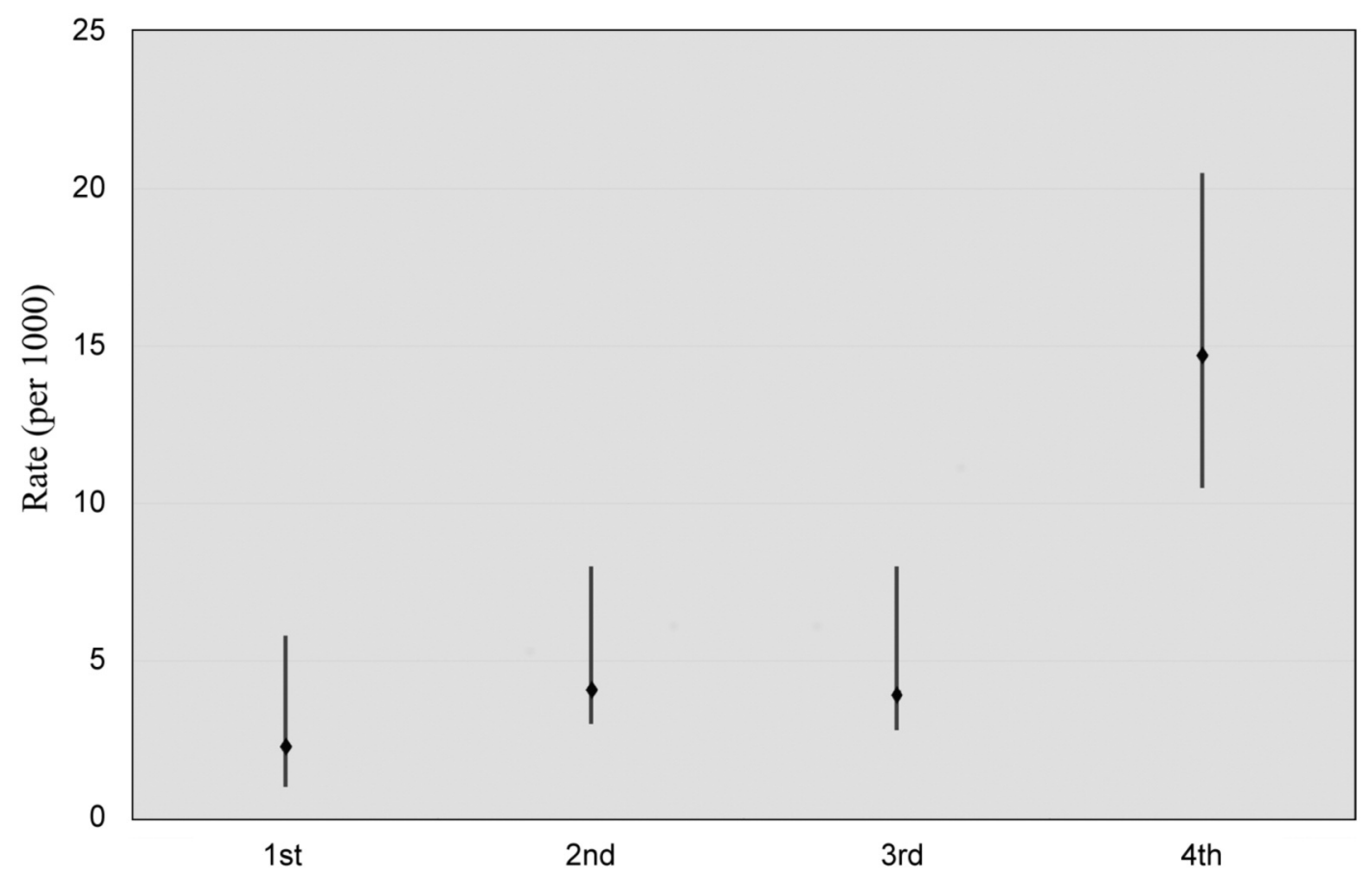

Figure 2. Incidence rates per 1,000 per year and per time period. $\left(1^{\text {st }}\right.$ period $=J a n 2009-D e c 2010,2^{\text {nd }}$ period=Jan 2011-Dec 2012, $3^{\text {rd }}$ period $=$ Jan 2013-Dec 2014, $4^{\text {th }}$ period=Jan 2015-Dec 2016)

difficulties, in 11 cases $(21.5 \%)$ to school/family bullying, in 9 cases $(17.6 \%)$ to family financial problems and in 9 cases $(17.6 \%)$ to child anxiety disorders (Figure 3 ). In eight (15.6\%) and in 3 cases $(5.8 \%)$, parental divorce and death appeared to be the responsible trigger, respectively. When demographics and clinical characteristics of the children with THC were compared between the last periods and all the others, a significant increase was found in bullying $(32.4 \%$ vs. $0 \%, p=0.006$, Figure 3). Additionally, cases of the last period were found to be associated with a lower proportion of ever wheezing episodes $(2.9 \%$ vs. $23.5 \%, p=0.03)$ and belonged to families whose fathers were highly educated (73.5\% vs. $41.2 \%, p=0.024)$. The proportion of jobless fathers was similar in both lower and higher educational levels $(p>0.05)$. However, children of highly educated fathers exhibited greater anxiety levels. (50\% vs. $16.7 \%, p=0.039)$.

\section{Discussion}

The number of children diagnosed in our specialized Unit with THC significantly increased during the 8 years of financial crisis in Greece, exceeding the incidence of previous reports $(5,11-16)$. Over an 18-year period, only 62 cases were reported by the Mayo Clinic (5). In 1991, Lokshin et al. analyzed 4,500 pediatric medical records and found only 9 cases of THC in a 12-year period (11). Houstek et al. reported ten cases between 1971 and 1981 (13).
Likewise, Cohlan and Stone reported only 33 cases of THC in over 25 years of clinical practice (14). Later, Wolff, from the same department, described another two patients and mentioned a total of six, 4 years after the original report (15). In a study conducted in a Swedish community sample with a quite high frequency of tics, the prevalence of chronic vocal tics, including cough, was $0.3 \%$ in girls and $0.7 \%$ in boys, among children aged 7 to 15 years (16).

Since 1966, when this entity was first identified, the reported prevalence of $\mathrm{THC}$ has been quite low, probably because of the low medical community awareness and the lack of validated diagnostic criteria $(8,12,25)$. Therefore, it was probably under-diagnosed and, hence, under-reported. Thus, a high index of suspicion of the medical personnel is an important factor for the diagnosis, as mentioned by Weinberger et al., who recently reported 140 pediatric patients with THC in the last 20 years (17). They claimed that laboratory tests were not needed to support the diagnosis and that could be based on history and observation alone. Similarly, in our study, a high awareness of this particular entity led to a diagnosis of THC based not just on the criteria shown in Table I but, mainly, on the history of repetitive coughing, ranging from several hours at a time to all day long, yet completely absent during sleep. In our series, we found a significant increase in THC cases as two thirds of them were reported in the last two years, when the stressful impact of the financial crisis was heavily felt in the Greek 
Table II. Social, demographic characteristics, and laboratory tests of the children with tic habit cough.

\begin{tabular}{|c|c|c|c|}
\hline Characteristic & No $(\%)$ & Test & No $(\%)$ \\
\hline Total group & 51 & Absolute eosinophilic & $1(1.9)$ \\
\hline Gender (girls) & $26(50.9)$ & number $>500$ & \\
\hline \multirow[t]{2}{*}{ Age } & $9.50 \pm 3.16$ & Immunoglobulin IgE & \\
\hline & & $<100 \mathrm{KU} / 1$ & $39(76.4)$ \\
\hline \multirow[t]{2}{*}{ BMI } & $19.5 \pm 3.9$ & $100<\operatorname{IgE}<300 \mathrm{KU} / 1$ & $6(11.7)$ \\
\hline & & $>300 \mathrm{KU} / 1$ & $1(1.9)$ \\
\hline \multirow[t]{4}{*}{ Months since cough started until diagnosis } & $12.82 \pm 13.89$ & Skin prick test & \\
\hline & & Positive & $3(5.8)$ \\
\hline & & Perennial & $2(3.9)$ \\
\hline & & Pollen & $2(3.9)$ \\
\hline Presenting symptom & $51(100)$ & Normal chest X-ray & $51(100)$ \\
\hline Cough & $3(5.8)$ & Normal lung function test & $51(100)$ \\
\hline+ Dyspnea & $1(1.9)$ & & \\
\hline +Sternal pain & $3(5.8)$ & & \\
\hline +Other tics & $8(15.6)$ & & \\
\hline \multicolumn{4}{|l|}{ Recent respiratory infection } \\
\hline Lifetime asthma & $12(23.5)$ & ( 3 cases $)$ & \\
\hline Asthma last year & $1(1.9)$ & ENT laryngoscopy: & Normal \\
\hline Lifetime allergic rhinitis & $3(5.8)$ & Nasal eosinophils: & Negative \\
\hline Allergy rhinitis last year & - & Mannitol provocation test: & Negative \\
\hline Lifetime atopic dermatitis & $1(1.9)$ & & \\
\hline Atopic dermatitis last year & - & & \\
\hline Atopic history in family & $11(21.6)$ & (a case each) & \\
\hline Smoking habit in family & $26(50.9)$ & Bronchoscopy: & Non-specific \\
\hline Smoking at home & $15(29.4)$ & & Inflammation \\
\hline High educated parents & $13(25.4)$ & Sinus Computer tomography: & Normal \\
\hline At least one parent lost his/her job & $12(23.5)$ & & \\
\hline Phychogenic disorders in family & $6(11.7)$ & & \\
\hline Depression & $4(7.8)$ & & \\
\hline Alcohol addiction & $1(1.9)$ & & \\
\hline Tic-habit cough & $1(1.9)$ & & \\
\hline
\end{tabular}

society. A clear increasing trend from 2.2 to 4.5 cases per year was found, represented by a much steeper slope of the increase in THC cases than that of the earlier years.

Past or current history of wheezing was not related to cough in the context of THC. Furthermore, all clinical and laboratory evaluations in this study, as in earlier ones, failed to reveal any underlying pathology. Radiologic imaging, immune studies, and pulmonary function tests were all negative. Flexible bronchoscopy, when performed, showed non-specific mucosal inflammation and EDAC during spontaneous breathing (7). Rabin et al. also noted lingual tonsils edema, impinging on the epiglottis and obliterating the vallecular space (1). These findings probably represent the consequence of aggressive, barking cough, traumatizing the mucosa, rather than its cause.

So far, five stressors have been most implicated in children's THC, all reflecting the western modernized way of living $(7,25)$. In particular, peer pressure, striving for high academic achievement, learning difficulties with consequential school phobia, bullying, divorce and/or a relative's death. In our study, learning difficulties were the major trigger. As high as $30 \%$ of children with learning disabilities have been reported to have behavioral and emotional problems such as attention deficit hyperactivity disorder, depression, anxiety, suicide ideation or substance abuse (26). Other cases experienced learning problems due to parents' pressure for high academic achievement resulting in family quarrels, strained relationships and children with low self-confidence. Bullying at school was the second most frequent trigger and the only factor that had a close relationship with the increase in THC cases. Bullying increased significantly during the last years of the Greek financial crisis $(27,28)$. The prevalence of the reported bullying victimization was associated with living in a main urban center, presence of a person with a chronic illness at home, poor family economic status and increased number of adults at home. Severe forms of physical and emotional aggression have been considered as a major emotional destabilizing factor. Bullying-victims were generally aggressive, uncooperative and prone to demonstrate 
a)

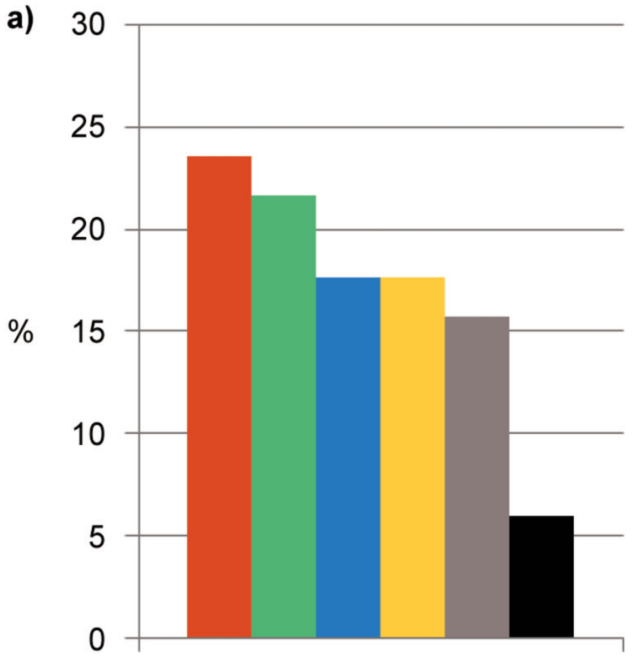

Stress triggers b)

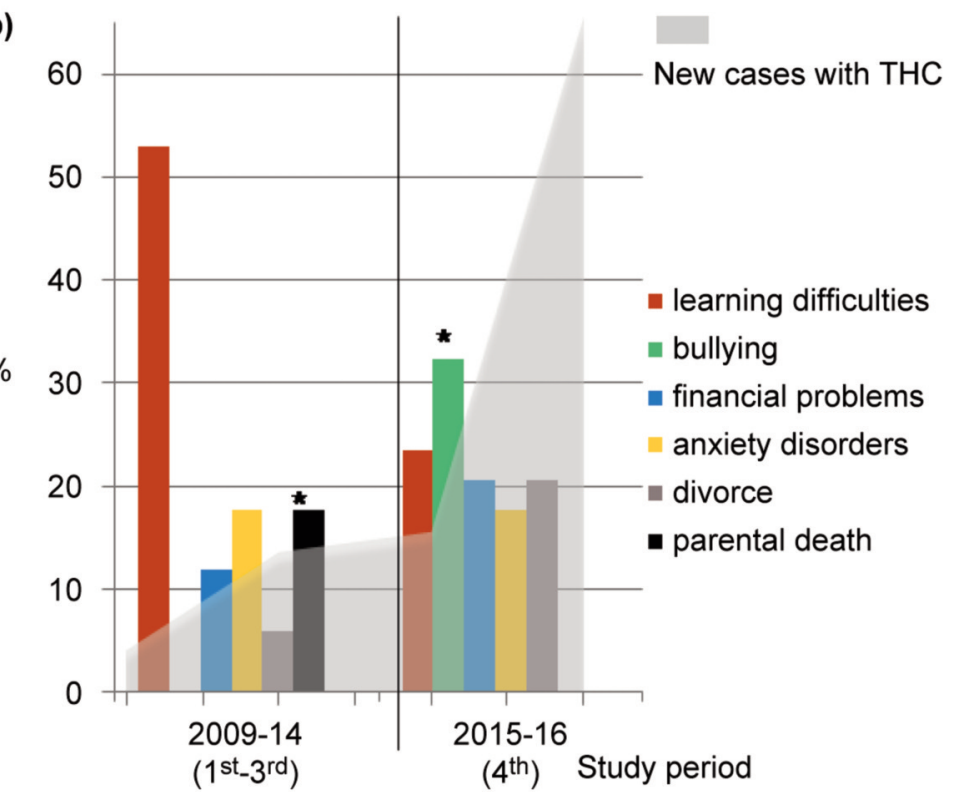

Figure 3. The stressful triggers that were responsible for tic habit cough in children (A) and the differences in the underlying stressful events between the $1^{\text {st }}-3^{\text {rd }}(2009-14)$ and $4^{\text {th }}(2015-16)$ period $(B) . * p<0.05$.

concurrently attention-deficit hyperactivity disorder, depression or anxiety and long-term post-traumatic stress disorders $(29,30)$. The present study may indicate that there is a close relationship between bullying and THC increase, which seems to be a desperate "cry" for help.

Financial difficulties emerged as a novel trigger factor during the study period. One fifth of our children with THC reported that one or both parents had lost their jobs and experienced serious financial problems. Several past publications have dealt with the influence of poverty on health status in low-income countries, but few studies have examined its influence in a rapidly declining economy in western countries $(31,32)$. This report enhanced previous national data dealing with children from western developed countries that experienced abrupt and serious financial constraints, which strongly influenced their mental health status (33). Our study highlights the indirect association between highly educated fathers who cope with financial problems and THC. One possible explanation could be the fact that this particular population experienced and spread more anxiety and depression. This was also reported by Barbaglia et al., who found that job loss increased the risk of any mental disorder in men (34). It seemed that highly educated parents were less able to effectively handle abrupt financial deteriorations (35). The aforementioned associations, maybe, reflect a more stressful environment in children of more educated fathers. On the other hand, poverty in childhood has been linked to emotional dysregulation throughout adulthood, and has been associated with pervasive negative physical and psychological health sequelae. Kim et al. provided evidence of prospective associations between childhood poverty at the age of 9 years and adult neural activity during effortful attempts to control negative emotions (36). The fact that exposure to poverty in early childhood has deleterious impact on brain development, restricting the ability to respond adaptively to emotional challenges in adulthood, further highlights the importance of this finding on child psychological development (37).

The present study has certain limitations. The cases described were derived from a major pediatric pulmonology center and thus, the prevalence and incidence rates were not representative of the general population. At first glance, the significant increase in incidence could be attributed to the increased awareness of the specialized medical personnel of our department. However, if this was the case, we would have expected a similar increasing trend in the incidence rates throughout the study period, a fact that was not observed. On the contrary, in the last 2 years, the incidence duplicated, suggesting additional triggers coming into play other than asthma or allergy. The identification of stressful events could not be clearly recalled in cases in which the diagnosis was delayed. The parents were asked to relate the onset of cough with a specific event retrospectively, which might have caused bias. In addition, the number of cases under study was small and thus, no clear etiologic correlation could be found between the stressors and THC. Moreover, the anxiety profile of these cases was unknown prior to the THC diagnosis, thus reported events might have acted as triggers on an unbalanced psychological background. 


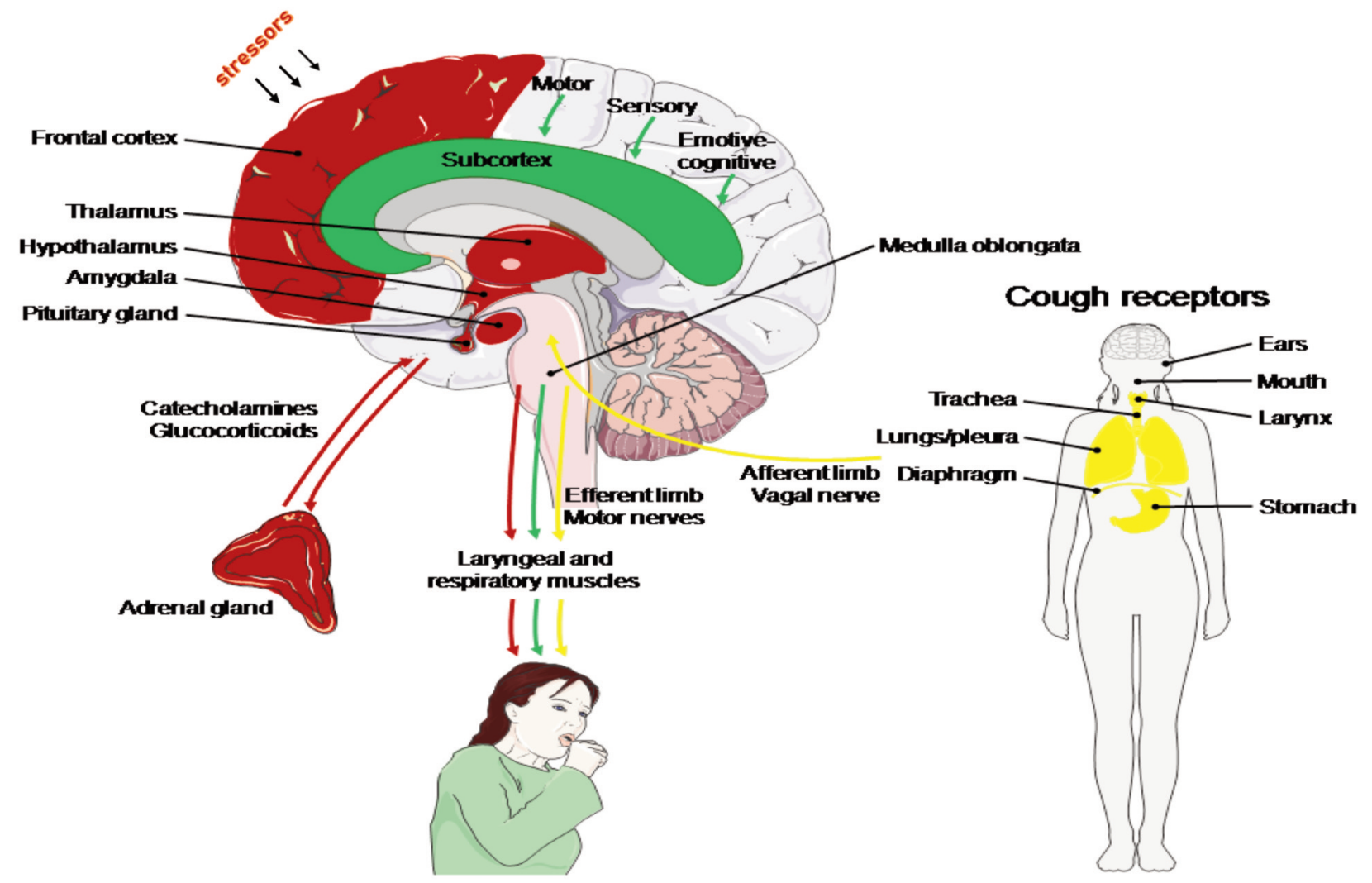

Figure 4. Cough reflex pathways. Psychophysiology of cough is shown through the interactions of cough reflex with the cortex and subcortex. A) Cough reflex pathway (yellow areas and lines): impulses from stimulated cough receptors traverse an afferent signal via the vagus nerve to the cough center in the medulla oblongata and generate an efferent signal that travels down the vagus, phrenic and spinal motor nerves to muscles of expiration producing cough. B) Cortical and subcortical pathway (green areas and lines): cough can also be regulated by cortical and subcortical pathways initiated by cognitive, motor or sensory neurons. C) Stress and limbic pathways (red areas and lines): Frontal cortex and amygdala, the brain structures that are involved in dealing with stress and fear, stimulate the thalamus, pituitary and adrenal cortex to release stress hormone such as glucocorticoids and catecholamines. Meanwhile, the amygdala act on the medulla oblongata and the efferent limb of cough reflex, stimulating the laryngeal and respiratory muscles.

The mechanisms behind stress-induced THC are incompletely understood. Children, under stressful conditions, tend to reproduce a physical symptom they are familiar with, cough being the commonest during the various respiratory infections of early life $(7,24)$. Both the neuroendocrine and the immune systems are activated during stress as part of the adaptive response that maintains homeostasis (38-40). Stress primes neural and inflammatory processes in the brain and peripheral organs, including components of the cough reflex. In the last thirty years, ion channels of the Transient Receptor Potential (TRP) class have been implicated in the afferent sensory loop of the cough reflex and in the heightened cough sensitivity seen in disease (41). Agonists of the TRP vanilloid 1 (TRPV1) capsaicin receptor such as vanilloids and protons are amongst the most potent chemicals that cause cough. Multiple single nucleotide polymorphisms of TRPVI gene are associated with cough sensitivity to capsaicin in healthy subjects and in cases with chronic refractory cough (42). Since it is broadly expressed in brain neurons and glia, TRPV1 acts as a regulator of neuronal activity and synaptic plasticity, through regulating long-term potentiation (LTP) and long-term depression (LTD) of synapse activity in the brain, therefore it may play a role in neurological and psychiatric disorders (43). Moreover, TPRV1 channels have been recently recognized to constitute an atypical neurotransmission system involved in functions such as addiction, anxiety, mood and cognition/learning (44, 45).

As a consequence, cough reflex is a complex neural reflex arc under both voluntary and involuntary control that is sub-served by stimulation of cough receptors in the upper and lower respiratory track. The broad knowledge is that impulses from stimulated cough receptors traverse an afferent pathway via the vagus nerve to a 'cough center' in 
the medulla oblongata (Figure 4, yellow line). The cough center generates an efferent signal that travels down the vagus, phrenic, and spinal motor nerves to expiratory muscles producing cough. However, cough is also regulated by cortical and subcortical pathways initiated by cognitive, motor and sensory neurons (46). These pathways can exert inhibitory signals suppressing cough (as during a live performance) and voluntary excitatory signals (as coughing upon request) (Figure 4, green line). Moreover, cough may be a manifestation of stress activating the fear pathway. The brain structures involved in dealing with stress and fear are the frontal cortex and the amygdala, which stimulate the stress system, including the hypothalamus, pituitary gland and adrenal cortex to release stress hormones, such as cortisol, as well as the arousal and noradrenergic centers of the autonomic nervous system in the brainstem, to release other stress hormones, such as the catecholamines (norepinephrine and epinephrine) (Figure 4, red line). Meanwhile, the activated amygdala may possibly act on the medulla oblongata via TRPV1 channels to activate the efferent limb of the cough reflex, through stimulation of the laryngeal and respiratory muscles.

The range of cortical control falls within limits determined by involuntary self-regulatory physiologic mechanisms and vice versa, as involuntary cough can be suppressed voluntarily, while both can be modified by Pavlovian (classical) and operant conditioning procedures (47). Classical conditioning is an established method of learning, whereby a conditioned stimulus is paired with an unconditioned one. For example, a child with learning difficulties feels uncomfortable and initially starts coughing during class. Later, however, the child would cough whenever a stimulus reminds him/her of school, such as the sound of the alarm clock in the morning or the school bus bell. On the other hand, operant conditioning is a type of learning in which the strength of a behavior is modified by the behavior's consequences, such as a reward or punishment, for instance, a child coughing may be picked up earlier from school.

Taking advantage of the direct influence and the physiologic correlation between the higher cortical areas and the lower cough reflex center, manipulation of the higher brain has been used therapeutically to suppress anxiety. Behavioral therapy has been recognized as an effective way of altering emotions in anxiety-related disorders (48). The premise behind behavioral therapy is that the unwanted behavior that was involuntarily used for a secondary gain can be un-learned. The goal is to help the child learn new, positive and distractional behaviors, which minimize or eliminate stress. The therapist teaches the child specific cognitive behavioral techniques, such as repeating positive statements, performing relaxed breathing, drinking water, registering of "cough attacks" in a calendar and escaping from or coping with a stressful activity. It should be noted that the mere reassurance that there is no serious underlying organic pathology, usually liberates the child and relieves the parents (49). When the possible stressful trigger factors are pointed out and the proper advice is followed, the psychological pressure and the cough substantially decrease, usually without recurrence. The prompt and favorable response to cognitive behavioral therapy in children further supports the diagnosis of THC $(8,10)$. Another proposed effective therapeutic intervention in children is the Suggestion Therapy $(24,50)$. On rare occasions, when family history is positive for serious psychiatric disorders, appropriate medication may be used.

In conclusion, the incidence of THC has significantly increased in recent years, reflecting the adverse consequences of modern life style, negatively affecting the health status of children. Family financial problems were found to be a new stressor for THC, but bullying seemed to be the only factor that had a close relationship with its increase, both demanding reforms in public health policy and practice. The findings of this study suggest that clinicians' awareness of the condition is the key to diagnosis and efforts should be made to recognize THC early. The sound knowledge of the clinical criteria may discern between organic, tic and 'somatized' respiratory symptoms in everyday practice, thus minimizing unnecessary diagnostic procedures on one hand, and the administration of ineffective, potentially harmful, therapeutic interventions, on the other. The psychophysiological mechanisms behind stress-induced THC may involve interactions among the higher cortical areas, the amygdala and the cough reflex center, thus explaining the successful therapeutic intervention achieved by cognitive behavioral therapy. Prompt and proper diagnosis as well as psychological support of children with THC will relieve the high pressure exerted on affected families.

\section{Funding}

This research did not receive any specific grant funding from agencies in the public, commercial, or not-for-profit sectors.

\section{Conflicts of Interest}

The Authors declare that there are no potential conflicts of interest regarding this study.

\section{Authors' Contributions}

P.A. conceptualized and designed the study, interpretated the results and drafted the initial manuscript. M.T.D. carried out the literature search, drafted some part of the manuscript, and reviewed the manuscript. G.G. carried out the psychiatric analysis and evaluation. T.O. carried out the psychological evaluation, the behavioral cognitive therapy and the follow up of the children and their families. D.H. 
designed and supervised data collection. Y.C. and C.P.G. interpretated the final results, reviewed and critically revised the manuscript. All the Authors approved the final version as submitted.

\section{Acknowledgements}

The Authors thank the statistician Mrs Chara Tzavara for the data analysis and Mrs Demy Bartouli and Cathy Lazarou for English editing the manuscript. The Authors would also like to thank the parents and children who accepted to be psychologically evaluated and consented to participate in this study.

\section{References}

1 Rabin CB: Disturbances of respiration of functional origin. J Asthma Res 5(4): 295-308, 1968. PMID: 5666106. DOI: $10.3109 / 02770906809100347$

2 Kravitz H, Gomberg RM, Burnstine RC, Hagler S and Korach A: Psychogenic cough tic in children and adolescents. Nine case histories illustrate the need for re-evaluation of this common but frequently unrecognized problem. Clin Pediatr (Phila) 8(10): 580583, 1969. PMID: 5344422. DOI: 10.1177/000992286900801009

3 Munford PR and Liberman RP: Differential attention in the treatment of operant cough. J Behav Med 1(3): 289-295, 1978 PMID: 755863. DOI: 10.1007/BF00846680

4 Weinberg EG: 'Honking': Psychogenic cough tic in children. S Afr Med J 57(6): 198-200, 1980. PMID: 7361211

5 Rojas AR, Sachs MI, YungingerJW andO'Connell EJ: Childhood involuntary cough syndrome: a long-term follow-up study. Ann Allergy66:106 (abstract), 1991.

6 Irwin RS, Glomb WB, Chang AB. Habit cough, tic cough, and psychogenic cough in adult and pediatric populations: ACCP evidence-based clinical practice guidelines. Chest. 2006 Jan; 129(1 Suppl): 174S-179S. doi: 10.1378/chest.129.1_suppl.174S PMID: 16428707

7 Weinberger M: The habit cough syndrome and its variations. Lung 190(1): 45-53, 2012. PMID: 21842256. DOI: 10.1007/ s00408-011-9317-0

8 Vertigan AE, Murad MH, Pringsheim T, Feinstein A, Chang AB, Newcombe PA, Rubin BK, McGarvey LP, Weir K, Altman KW, Weinberger M, Irwin RS, Adams TM, Altman KW, Barker AF, Birring SS, Blackhall F, Bolser DC, Boulet LP, Braman SS, Brightling C, Callahan-Lyon P, Canning BJ, Chang AB, Coeytaux R, Cowley T, Davenport P, Diekemper RL, Ebihara S, El Solh AA, Escalante P, Feinstein A, Field SK, Fisher D, French CT, Gibson P, Gold P, Gould MK, Grant C, Harding SM, Harnden A, Hill AT, Irwin RS, Kahrilas PJ, Keogh KA, Lane AP, Lim K, Malesker MA, Mazzone P, Mazzone S, McCrory DC, McGarvey L, Molasiotis A, Murad MH, Newcombe P, Nguyen HQ, Oppenheimer J, Prezant D, Pringsheim T, Restrepo MI, Rosen M, Rubin B, Ryu JH, Smith J, Tarlo SM, Vertigan AE, Wang G, Weinberger M, Weir K, Wiener RS and CHEST Expert Cough Panel.: Somatic cough syndrome (previously referred to as psychogenic cough) and tic cough (previously referred to as habit cough) in adults and children: CHEST guideline and expert panel report. Chest 148(1): 24-31, 2015. PMID: 25856777. DOI: 10.1378/chest.15-0423

9 Weinberger $\mathrm{M}$ and Fischer A: Differential diagnosis of chronic cough in children. Allergy Asthma Proc 35(2): 95-103, 2014. PMID: 24717785. DOI: 10.2500/aap.2014.35.3711
10 Haydour Q, Alahdab F, Farah M, Barrionuevo P, Vertigan AE, Newcombe PA, Pringsheim T, Chang AB, Rubin BK, McGarvey L, Weir KA, Altman KW, Feinstein A, Murad MH and Irwin RS: Management and diagnosis of psychogenic cough, habit cough, and tic cough: A systematic review. Chest 146(2): 355-372, 2014. PMID: 24833061. DOI: 10.1378/chest.14-0795

11 Lokshin B, Lindgren S, Weinberger M and Koviach J: Outcome of habit cough in children treated with a brief session of suggestion therapy. Ann Allergy 67(6): 579-582, 1991. PMID: 1750719.

12 Berman BA: Habit cough in adolescent children. Ann Allergy 24(1): 43-46, 1966. PMID: 5902120.

13 Houstěk J, Vyhnálek M, Suková B and Copová M: [Psychogenic cough]. Cesk Pediatr 38(7): 405-410, 1983. PMID: 6616695.

14 Cohlan SQ and Stone SM: The cough and the bedsheet. Pediatrics 74(1): 11-15, 1984. PMID: 6739203.

15 Wolff PS: An ingenious way to treat psychogenic cough. MCN Am J Matern Child Nurs 13(2): 118-120, 1988. PMID: 3128700

16 Khalifa $\mathrm{N}$ and von Knorring AL: Prevalence of tic disorders and Tourette syndrome in a Swedish school population. Dev Med Child Neurol 45(5): 315-319, 2003. PMID: 12729145. DOI: $10.1017 / \mathrm{s} 0012162203000598$

17 Weinberger $\mathrm{M}$ and Hoegger $\mathrm{M}$ : The cough without a cause: Habit cough syndrome. J Allergy Clin Immunol 137(3): 930931, 2016. PMID: 26483178. DOI: 10.1016/j.jaci.2015.09.002

18 American Psychiatric Association: Diagnostic and statistical manual of mental disorders. $5^{\text {th }}$ ed.Arlington, VA: American PsychiatricAssociation; 2013. DOI: 10.1176/appi.books. 9780890425596

19 Hamilton Anxiety Rating Scale (HAM-A). Available at: https://dcf.psychiatry.ufl.edu/files/2011/05/HAMILTONANXIETY.pdf [Last accessed on February 26, 2021]

20 Matza LS, Morlock R, Sexton C, Malley K and Feltner D: Identifying HAM-A cutoffs for mild, moderate, and severe generalized anxiety disorder. Int J Methods Psychiatr Res 19(4): 223-232, 2010. PMID: 20718076. DOI: 10.1002/mpr.323

21 Oh DL, Jerman P, Purewal Boparai SK, Koita K, Briner S, Bucci $\mathrm{M}$ and Harris NB: Review of tools for measuring exposure to adversity in children and adolescents. J Pediatr Health Care 32(6): 564-583, 2018. PMID: 30369409. DOI: 10.1016/ j.pedhc.2018.04.021

22 Shaw T, Dooley JJ, Cross D, Zubrick SR and Waters S: The forms of bullying scale (FBS): validity and reliability estimates for a measure of bullying victimization and perpetration in adolescence. Psychol Assess 25(4): 1045-1057, 2013. PMID: 23730831. DOI: $10.1037 / \mathrm{a} 0032955$

23 Whiteside SPH, Sim LA, Morrow AS, Farah WH, Hilliker DR, Murad MH and Wang Z: A meta-analysis to guide the enhancement of CBT for childhood anxiety: Exposure over anxiety management. Clin Child Fam Psychol Rev 23(1): 102121, 2020. PMID: 31628568. DOI: 10.1007/s10567-01900303-2

24 Schwartz C, Barican JL, Yung D, Zheng Y and Waddell C: Six decades of preventing and treating childhood anxiety disorders: A systematic review and meta-analysis to inform policy and practice. Evid Based Ment Health 22(3): 103-110, 2019. PMID: 31315926. DOI: 10.1136/ebmental-2019-300096

25 Grüber C, Lehmann C, Weiss C and Niggemann B: Somatoform respiratory disorders in children and adolescents-proposals for a practical approach to definition and classification. Pediatr 
Pulmonol 47(2): 199-205, 2012. PMID: 21905261. DOI: 10.1002/ppul.21533

26 Sahoo MK, Biswas $\mathrm{H}$ and Padhy SK: Psychological comorbidity in children with specific learning disorders. J Family Med Prim Care 4(1): 21-25, 2015. PMID: 25810984. DOI: 10.4103/2249-4863.152243

27 Pervanidou P, Makris G, Bouzios I, Chrousos G, Roma E and Chouliaras G: Bullying victimization: Associated contextual factors in a Greek sample of children and adolescents. Psychiatriki 30(3): 216-225, 2019. PMID: 31685453. DOI: 10.22365/jpsych.2019.303.216

28 Plexousakis SS, Kourkoutas E, Giovazolias T, Chatira K and Nikolopoulos D: School bullying and post-traumatic stress disorder symptoms: The role of parental bonding. Front Public Health 7: 75, 2019. PMID: 31024876. DOI: 10.3389/fpubh. 2019.00075

29 Miller-Perrin CL, Perrin RD and Kocur JL: Parental physical and psychological aggression: Psychological symptoms in young adults. Child Abuse Negl 33(1): 1-11, 2009. PMID: 19167070. DOI: $10.1016 /$ j.chiabu.2008.12.001

30 Kumpulainen K: Psychiatric conditions associated with bullying. Int J Adolesc Med Health 20(2): 121-132, 2008. PMID: 18714551. DOI: 10.1515/ijamh.2008.20.2.121

31 Aber JL, Bennett NG, Conley DC and Li J: The effects of poverty on child health and development. Annu Rev Public Health 18: 463-483, 1997. PMID: 9143727. DOI: 10.1146/ annurev.publhealth.18.1.463

32 Kleanthous K, Dermitzaki E, Papadimitriou DT,Papaevangelou $\mathrm{V}$ and Papadimitriou A: Overweight and obesity decreased in Greek schoolchildren from 2009 to 2012 during the early phase of the economic crisis. ActaPaediatr 105(2): 200-205, 2016. DOI:10.1111/apa.13143

33 Paleologou MP, Anagnostopoulos DC, Lazaratou H, Economou M, Peppou LE and Malliori M: Adolescents' mental health during the financial crisis in Greece: The first epidemiological data. Psychiatriki 29(3): 271-274, 2018. PMID: 30605432. DOI: 10.22365/jpsych.2018.293.271

34 Barbaglia MG, ten Have M, Dorsselaer S, Alonso J and de Graaf R: Negative socioeconomic changes and mental disorders: A longitudinal study. J Epidemiol Community Health 69(1): 55-62, 2015. PMID: 25205161. DOI: 10.1136/jech-2014-204184

35 Ananat EO, Gassman-Pines A, Francis DV and Gibson-Davis CM: Linking job loss, inequality, mental health, and education. Science 356(6343): 1127-1128, 2017. PMID: 28619903. DOI: 10.1126/science.aam5347

36 Kim P, Evans GW, Angstadt M, Ho SS, Sripada CS, Swain JE, Liberzon I and Phan KL: Effects of childhood poverty and chronic stress on emotion regulatory brain function in adulthood. Proc Natl Acad Sci USA 110(46): 18442-18447, 2013. PMID: 24145409. DOI: $10.1073 /$ pnas.1308240110

37 Liberzon I, Ma ST, Okada G, Ho SS, Swain JE and Evans GW: Childhood poverty and recruitment of adult emotion regulatory neurocircuitry. Soc Cogn Affect Neurosci 10(11): 1596-1606, 2015. PMID: 25939653. DOI: $10.1093 /$ scan/nsv045

38 Chrousos GP: The hypothalamic-pituitary-adrenal axis and immune-mediated inflammation. N Engl J Med 332(20): 13511362, 1995. PMID: 7715646. DOI: 10.1056/NEJM199505 183322008
39 Chrousos GP: Stress and disorders of the stress system. Nat Rev Endocrinol 5(7): 374-381, 2009. PMID: 19488073. DOI: 10.1038/nrendo.2009.106

40 Stavrou S, Nicolaides NC, Critselis E, Darviri C, Charmandari E and Chrousos GP: Paediatric stress: from neuroendocrinology to contemporary disorders. Eur J Clin Invest 47(3): 262-269, 2017. PMID: 28074555. DOI: 10.1111/eci.12724

41 Groneberg DA, Niimi A, Dinh QT, Cosio B, Hew M, Fischer A and Chung KF: Increased expression of transient receptor potential vanilloid-1 in airway nerves of chronic cough. Am J Respir Crit Care Med 170(12): 1276-1280, 2004. PMID: 15447941. DOI: $10.1164 / \mathrm{rccm} .200402-1740 C$

42 Long L, Yao H, Tian J, Luo W, Yu X, Yi F, Chen Q, Xie J, Zhong N, Chung KF and Lai K: Heterogeneity of cough hypersensitivity mediated by TRPV1 and TRPA1 in patients with chronic refractory cough. Respir Res 20(1): 112, 2019. PMID: 31170994. DOI: 10.1186/s12931-019-1077-z

43 Gibson HE, Edwards JG, Page RS, Van Hook MJ and Kauer JA: TRPV1 channels mediate long-term depression at synapses on hippocampal interneurons. Neuron 57(5): 746-759, 2008. PMID: 18341994. DOI: 10.1016/j.neuron.2007.12.027

44 Marsch R, Foeller E, Rammes G, Bunck M, Kössl M, Holsboer F, Zieglgänsberger W, Landgraf R, Lutz B and Wotjak CT: Reduced anxiety, conditioned fear, and hippocampal long-term potentiation in transient receptor potential vanilloid type 1 receptor-deficient mice. J Neurosci 27(4): 832-839, 2007. PMID: 17251423. DOI: 10.1523/JNEUROSCI.3303-06.2007

45 Edwards JG: TRPV1 in the central nervous system: synaptic plasticity, function, and pharmacological implications. Prog Drug Res 68: 77-104, 2014. PMID: 24941665. DOI: 10.1007/978-3-0348-0828-6_3

46 Canning BJ, Chang AB, Bolser DC, Smith JA, Mazzone SB, McGarvey L and CHEST Expert Cough Panel.: Anatomy and neurophysiology of cough: CHEST Guideline and Expert Panel report. Chest 146(6): 1633-1648, 2014. PMID: 25188530. DOI: 10.1378/chest.14-1481

47 Maren S: Neurobiology of Pavlovian fear conditioning. Annu Rev Neurosci 24: 897-931, 2001. PMID: 11520922. DOI: 10.1146/annurev.neuro.24.1.897

48 Crowe K and McKay D: Efficacy of cognitive-behavioral therapy for childhood anxiety and depression. J Anxiety Disord 49: 76-87, 2017. PMID: 28460329. DOI: 10.1016/j.janxdis. 2017.04.001

49 Wright MFA and Balfour-Lynn IM: Habit-tic cough: Presentation and outcome with simple reassurance. Pediatr Pulmonol 53(4): 512-516, 2018. PMID: 29363880. DOI: 10.1002/ppul.23948

50 Weinberger M and Lockshin B: When is cough functional, and how should it be treated? Breathe (Sheff) 13(1): 22-30, 2017. PMID: 28289448. DOI: 10.1183/20734735.015216

Received February 12, 2021

Revised February 25, 2021

Accepted February 26, 2021 